\title{
PENGARUH KEADILAN ORGANISASIONAL TERHADAP KEPUASAN KERJA DAN KOMITMEN ORGANISASIONAL PADA DISPERKIM KOTA DENPASAR
}

\author{
Ni Putu Linda Pratiwi ${ }^{1}$ \\ Made Subudi ${ }^{2}$ \\ ${ }^{1,2}$ Fakultas Ekonomi dan Bisnis Universitas Udayana, Bali, Indonesia \\ Email: pratiwilinda4@gmail.com
}

\begin{abstract}
ABSTRAK
Tujuan penelitian ini adalah untuk mengetahui pengaruh keadilan organisasional terhadap kepuasan kerja dan komitmen organisasional di Disperkim Kota Denpasar. Penelitian ini dilakukan pada karyawan Disperkim Kota Denpasar. Sampel yang dipakai sebesar 100 responden. Pengambilan sampel pada penelitian ini memakai teknik proportionate random sampling. Pengumpulan data dilaksanakan dengan penyebaran kuisioner dengan memakai skala likert 5 poin dalam mengukur 28 item pernyataan. Teknik analisis yang dipakai yaitu Path Anaylsis. Hasil Analisis menunjukan bahwa keadilan organisasional memiliki pengaruh positif serta signifikan baik terhadap kepuasan kerja maupun komitmen organisasional. Kepuasan kerja memiliki pengaruh positif dan signifikan terhadap komitmen organisasional. Penelitian ini juga berhasil membuktikan bahwasannya kepuasan kerja menjadi mediasi pengaruh keadilan organisasional terhadap komitmen organisasional di Disperkim Kota Denpasar.
\end{abstract}

Kata kunci : keadilan organisasional, kepuasan kerja, komitmen organisasional

\begin{abstract}
The purpose of this study was to determine the effect of organizational justice on job satisfaction and organizational commitment in the Department of Housing and Settlements in Denpasar City. This research was conducted on employees of the Housing and Settlement Area and Denpasar City. Samples taken were 100 respondents. Sampling in this study used proportionate random sampling technique. Data collection was carried out by distributing questionnaires using a 5-point Likert scale to measure 28 statement items. The analytical technique used was an Islamic Path. The results of the analysis show that organizattional justice has a positive also significant effect on both job satisfaction and organizational committment. Job satisfaction has a positive and significant effect on organizational commitment. This study also succeeded in proving that job satisfaction mediates the influence of organizational justice on organizational committment in the Department of Housing, Settlements and Land Affairs of Denpasar City.
\end{abstract}

Keyword : organizational justice, job satisfaction, organizational commitment 


\section{PENDAHULUAN}

Pelayanan publik merupakan salah satu fungsi utama dalam program pemerintahan menurut umum termasuk bagian hidup yang cukup besar dan memiliki fungsi memberikan kebutuhan rakyat di ranah pendidikan, kesehatan, serta lain-lain. Di Indonesia, usaha membenarkan layanan sebetulnya juga sudah terlaksana oleh pemerintah. Tetapi, sampai saat ini rakyat masihlah mempunyai anggapan bahwasannya kualitas layanan publik masihlah amat kecil, khususnya untuk ke pelosok-pelosok. Dessler (2010:5) memberi pernyataan SDM merupakan kegiatan mendapatkan, memberi pelatihan, memberi penilaian serta menyerahkan kompensasi untuk pegawai, memperhatikan hubungan pekerjaan, kesehatan, keamanan juga masalah keadilan. Noe et al. (2010:5) memberikan pernyataan bahwasannya, Human Resource Management memakai acuan kebijakankebijakan, praktek-praktek, juga beberapa sistem yang memberi pengaruh pada prilaku, sikap, serta kinerja pegawai. Sdm yang mempunyai kualitas serta kompetitif mempunyai kaitan erat dengan kinerja karyawan didalam perusahaan, namun didalam penerapannya sdm didalam perusahaan banyak mempunyai keterbatasan. Sekian permasalahan ada didalam kesadaran akan tugas juga tanggung jawab pribadi tentang tugas pokok serta fungsi dari tiap-tiap pribadi didalam perusahaan, hingga diharuskan adanya usaha dari perusahaan dalam memberikan peningkatan kinerja karyawan agar tujuan perusahaan dapat tercapai.

Dinas perumahan, kawasan permukiman dan pertanahan Kota Denpasar merupakan institusi pemerintah yang menyediakan layanan untuk rakyat juga adalah sebuah media informasi untuk rakyat luas serta memiliki fungsi untuk 
Ni Putu Linda Pratiwi dan Made Subudi, Pengaruh Keadilan Organisasional...

menyambung informasi didalam proses penyampaian pendapat dengan rakyat. Dilihat dari uraian tugasnya semula menangani urusan penataan ruang dan proses perijinan menjadi urusan wajib penataan ruang dan perumahan. Memberikan rekomendasi pelayanan perijinan di Bidang perumahan, kawasan permukiman dan pertanahan sesuai dengan ketentuan yang berlaku sebagai dasar penerbitan ijin. Oleh karena hal tersebut, dibutuhkan karyawan yang memiliki kualitas tinggi, untuk itu karyawan harus bisa melaksanakan pekerjaan dengan baik, disiplin, kreatif, serta melakukan pekerjaan dalam team. Karyawan yang memiliki kualitas pelayanan yang baik dan professional sangat dituntut dalam dalam peningkatan mutu dari Disperkim Kota Denpasar.

Pada kondisi sebenarnya di Dinas Perumahan, Kawasan Permukian dan Pertanahan Kota Denpasar menurut pengamatan penelitian, terdapat masalah yaitu rendahnya komitmen dinas perumahan, kawasan permukian dan pertanahan Kota Denpasar. Karyawan yang memiliki komitmen yang rendah terhadap organisasi dapat menghambat tercapainya tujuan organisasi kondisi seperti ini akan berdampak buruk bagi disperkim Kota Denpasar dikarenakan oleh rendah komitmen organisasional yang memiliki arti loyalitas pegawai pada organisasi rendah juga memberi peningkatan rasa ingin pegawai dalam tak mempertahankan diri serta tingkat loyalitas yang kurang di organisasi. Indikasi dari rendahnya komitmen karyawan dalam organisasi dapat ditinjau dari tingkat keterlibatan karyawan dalam aktivitas organisasi dari hari ke hari, seperti ditunjukkan dalam tingkat kehadiran karyawan. Tingkat kehadiran karyawan Disperkim Kota Denpasar dapat dilihat pada Tabel 1. 
Tabel 1.

Tingkat Absensi Karyawan Dinas Perumahan, Kawasan Permukiman dan Pertanahan Kota Denpasar

\begin{tabular}{|c|c|c|c|c|c|c|c|c|c|}
\hline Bulan & $\begin{array}{l}\text { Jumlah } \\
\text { Pegawai }\end{array}$ & $\begin{array}{l}\text { Jumlah } \\
\text { Hari } \\
\text { Kerja } \\
\text { Efektif }\end{array}$ & $\begin{array}{c}\text { Total } \\
\text { Hari } \\
\text { Kerja } \\
\text { Efektif/ } \\
\text { Bulan } \\
\end{array}$ & & $\begin{array}{l}\text { Jumlal } \\
\text { Absens }\end{array}$ & & $\begin{array}{c}\text { Total } \\
\text { Absensi }\end{array}$ & $\begin{array}{c}\text { Jumlah Hari } \\
\text { Kerja } \\
\text { Terpenuhi/Bulan }\end{array}$ & $\begin{array}{c}\text { Persentase } \\
\text { Tingkat } \\
\text { Absensi } \\
(\%)\end{array}$ \\
\hline \multirow{2}{*}{$\mathbf{A}$} & \multirow{2}{*}{ B } & \multirow{2}{*}{ C } & \multirow{2}{*}{$\mathrm{D}=\mathrm{BxC}$} & \multicolumn{3}{|c|}{$\mathbf{E}$} & \multirow{2}{*}{$\mathbf{F}$} & \multirow{2}{*}{$G=D-F$} & \multirow{2}{*}{$H=F / D .100$} \\
\hline & & & & A & I & $\mathrm{S}$ & & & \\
\hline Agustus & 133 & 22 & 2926 & 7 & 150 & 42 & 199 & 2727 & 6,8 \\
\hline September & 133 & 17 & 2261 & 9 & 78 & 30 & 117 & 2144 & 5,17 \\
\hline Oktober & 133 & 21 & 2793 & 9 & 55 & 40 & 104 & 2689 & 3,72 \\
\hline
\end{tabular}

Hasil perhitungan tingkat absensi karyawan di Disperkim Kota Denpasar menunjukkan tingkat absensi karyawan di atas 3 persen yang berarti bahwa tingkat absensi yang terjadi di perusahaan cukup tinggi. Berpidahnya karyawan dari organisasi ke organisasi yang lain juga dapat menunjukkan rendahnya komitmen organisasional pada perusahaan. Suryanatha (2014) memberi penegasan kecilnya komitmen didalam sebuah perusahaan memberikan petunjuk sedikitnya tanggung jawab seorang pegawai didalam melakukan pekerjaanya, komitmen jadi lebih susah untuk dilaksanakan mengingat besarnya organisasi yang memakai sistim kontrak untuk pegawainya.

Pernyataan diatas juga bisa diketahui berdasarkan sikap karyawan yang hanya melakukan pekerjaan serta tanggung jawab dirinya sendiri tanpa mempunyai rasa ingin dalam menolong rekan kerja yang mempunyai beban kerja yang lebih dan condong dalam bekerja dengan individu serta itu bisa ditimbulkan daripada perbedaan para individual yang mencakup pengalaman, pengetahuan, pelatihan juga kesadaran akan sikap bekerja yang dipunyai. Di kondisi ideal, karyawan seharusnya mempunyai peran komitmen organiasional dengan memberi 
Ni Putu Linda Pratiwi dan Made Subudi, Pengaruh Keadilan Organisasional...

petunjuk prilaku sukarela agar ingin melaksanakan tugas ataupun pekerjaannya di luar tanggung jawab serta kewajiban agar tujuan perusahaan bias tercapai. Dikarenakan hal tersebut maka agar memberi peningkatan pada komitmen oranisasional dibuthkan adanya beberapa faktor yang memberi pengaruh, diantaranya kepuasan kerja juga keadilan organisasional.

Fernandes dan Awamleh (2006) memberi pernyataan bahwasannya, keadilan organisasi mempunyai peran yang genting dimana reward pasti dibagikan dengan cara adil sesuai bidang serta bisa didapatkan pada organisasi. Keadilan organisasional adalah faktor vital, dikarenakan imbalan yang didapatkan pada organisasi itu cocok degnan kinerja individu para pegawainya. Oceani dan Sriathi (2015) mnemukan hasil bahwasannya keadilan organisasional mempunyai pengaruh pada komitmen. Persepsi karyawan terhadap keadilan organisasional juga harus di perhatikan oleh perusahaan. Keadilan organisasional merupakan sebuah konsep perseimbangan yang diharap bisa diterapkan didalam perusahaan untuk melayani pegawai yang bertujuan untuk menimbulkan bertumbuhnya rasa komitmen didalam diri pegawai (Sutrisna dan Rahyuda, 2014). Penelitian yang dilakukan Malik dan Naeem (2011) menemukan keadilan distributif dan keadilan prosedural memiliki peran dalam menentukan komitmen dari anggota terhadap lembaga. Menariknya, keadilan prosedural tidak bertindak sebagai anteseden komitmen organisasional. Keadilan merupakan suatu hal yang sangat penting saat ini. Persoalan ketidakadilan merupakan faktor penyebab ketidakpuasan dan apabila hal tersebut tidak segera diselesaikan maka akan dapat menimbulkan perilaku yang menyimpang di tempat kerja. 
Al- Zubi (2010) memberi pernyataan bahwasannya pegawai akanlah merasakan kepuasan apabila kerjanya dianggap, hal itu ccok dengan kebijakan imbalan yang sudah dibentuk pada tiap-tiap organisasi. Kepuasan kerja mempunyai peranan vital didalam produktivitas pegawai serta memiliki dampak terhadap organisasi, jadi pegawai haruslah dilihat dengan serius juga wajib dibentuk sistim imbalan supaya mereka merasakan kepuasan juga kinerja yang dikerjakan bisa membuat kemajuan organisasi dikarenakan sdm merupakan aset berharga juga susah untuk mempertahankannya, jadi perusahaan haruslah memberi perhatian pada tiap-tiap faktor kepuasan kerja pegawai. Tania dan Sutanto (2013) memberi pernyataan bahwasannya kepuasan kerja mempunyai pengaruh pada komitmen organisasional. Fatimah et al. (2011) mendapatkan bahwasannya seseorang dapat memberi peningkatan rasa kepuasan dalam pekerjaannya bila rasa adil yang dirasa pegwai besar. Berdasarkan latar belakang dan penelitian sebelumnya, maka peneliti tertarik untuk meneliti pengaruh keadilan organisasional terhadap komitmen organisasional karyawan baik secara langsung maupun tidak langsung melalui kepuasan kerja sebagai variabel intervening pada karyawan di Disperkim Denpasar. Lokasi ini dipilih karena terdapat indikasi rendahnya komitmen organisasi yang dapat dilihat dari tingkat kehadiran karyawan.

Berdasarkan permasalahan yang telah diuraikan sebelumnya, rumusan masalah penelitian adalah sebagai berikut: 1) Bagaimanakah pengaruh keadilan organisasonal terhadap kepuasan kerja pada Disperkim Kota Denpasar? 2) Bagaimanakah pengaruh keadilan organisasional terhadap komitmen 
Ni Putu Linda Pratiwi dan Made Subudi, Pengaruh Keadilan Organisasional...

organisasional pada Disperkim Kota Denpasar? 3) Bagaimana pengaruh kepuasan kerja pada komitmen organisasional di Disperkim Kota Denpasar? 4) Bagaimanakah kepuasan kerja memediasi pengaruh keadilan organisasional pada komitmen organisasional pada Disperkim Kota Denpasar?

Tujuan penelitian berikut yaitu sebagai berikut: 1) Untuk mengetahui pengaruh keadilan organisasonal pada kepuasan kerja di Disperkim Kota Denpasar. 2) Untuk mengetahui pengaruh keadilan organisasional pada komitmen organisasional di Disperkim Kota Denpasar. 3) Untuk mengetahui pengaruh kepuasan kerja pada komitmen organisasional di Disperkim Kota Denpasar. 4) Untuk menganalisis kepuasan kerja memediasi pengaruh keadilan organisasional terhadap komitmen organisasional pada Disperkim Kota Denpasar.

Kegunaan yang diharapkan dari penelitian ini adalah sebagai berikut: 1) Hasil penelitian ini diharapkan dapat memberikan sumbangan terhadap perkembangan ilmu melalui data empiris dalam teori-teori yang berhubungan dengan ilmu sumber daya manusia khususnya mengenai Keadilan organisasional, kepuasan kerja, komitmen organisasional. 2) Hasil dari penelitian ini juga diharapkan dapat menjadi referensi bagi organisasi untuk menentukan kebijakan yang berkaitan dengan keadilan organisasional, kepuasan kerja, komitmen organisasional.

Persepsi karyawan terhadap keadilan dalam organisasi akan berdampak pada kepuasan kerja yang dirasakan oleh karyawan. Penelitian yang dilakukan oleh Fatt et al. (2010) menemukan bahwa keadilan distributive dan keadilan procedural berpengaruh positif dan signifikan terhadap kepuasan kerja. Penelitian 
yang dilaksanakan oleh Altahaynehet et al. (2014) pada sekolah umum di Yordania yang memperlibatkan guru penjas memberi petunjuk bahwasannya keadilan organisasional memiliki pengaruh dengan signifikan pada kepuasan kerja. Pandangan guru mengenai keadilan organisasional yaitu genting juga pasti mempunyai efek yang signifikan pada rasa puas mereka. Riset yang dilaksanakan oleh Putra (2014), mempunyai judul Pengaruh Keadilan Organisasional Di Kepuasan Kerja Sera Turnover Intention Pegawai BPR Di Kabupaten Tabanan memberi petunjuk bahwasannya keadilan 17 organisasional memiliki pengaruh positif untuk kepuasan kerja pegawai pada BPR kabupaten Tabanan. Putra (2014) organisasi haruslah menjaga serta sering memberi perhatian berapa besarnya rasa keadilan yang dirasa pegawainya serta kepuasan pegawai di pekerjaanya. Keadilan organisasional bisa terwujud oleh organisasi dengan memberi perhatian tiga dimensi keadilan didalam perusahaan adalah keadilan distributif, prosedural, serta interaksional hingga tiap pegawai bisa merasa adil yang cocok dengan hukum yang berlaku. Kepuasan kerja pegawai haruslah terus terjaga dengan baik bila inginkan membuat pegawai bertahan terus pada organisasi dikarenakan pegawai memiliki kecenderungan memilih kerja yang bisa membuat keinginan serta kepuasan mereka.

Hasil penelitian yang dilaksanakan oleh Fatimah et al. (2011) yang memiliki judul The Relationships between Organizational Justice, Organizatiional Citizenship Behavior and Job Sattisfaction mendapatkan hasil bahwasannya ada sebuah pengaruh yang signifikan dan positif daripada keadilan organisasional pada kepuasan kerja. Berikutnya berdasar hasil riset yang dilaksanakan oleh 
Ni Putu Linda Pratiwi dan Made Subudi, Pengaruh Keadilan Organisasional...

Sutrisna (2014) yang memiliki judul Pengaruh Keadilan Distributif, Prosedural, Dan Interaksional Terhadap Kepuasan Kerja Dan Komitmen Organisasional Pada Paramedis Di RS Tk II Udayana Denpasar hasilnya bahwasannya keadilan organisasional memiliki pengaruh positif serta signifikan pada kepuasan. Tiga konsep keadilan organisasional sangat betul bisa mempunyai pengaruh kepuasan bekerja seorang paramedis.

$\mathrm{H}_{1}$ : Keadilan organisasional memiliki pengaruh positif serta signifikan pada kepuasan kerja.

Keadilan organisasional akan berdampak pada komitmen karyawan terhadap organisasi. Penelitian yang dilakukan oleh Jawad et al. (2012) didalam penelitian yang memiliki judul Role of Organizational justice in organizational commitment with moderating effect of employee work attitudes bahwasannya ada pengaruh yang kuat diantara keadilan distributif, keadilan prosedur serta keadilan interaksi pada komitmen organisasional. Sikap bekerja mempunyai hubungan positif yang signifikan dengan komitmen organisasional, memberikan kekuatan hubungan yang memberi petunjuk ada pengaruh keadilan organisasi pada komitmen organisasional. Sikap kerja yang memberi pengaruh hubungan adalah sikap positif yang mengantarkan kearah komitmen serta pengawasan terkait komitmen dari pegawai. Bila manager memulai melakukan urusan dengan bawahannya dengan caranya yang adil serta amanah jadi mereka bisa memberi peningkatan komitmen pegawai juga ini hasil kinerja organisasi dengan keseluruhan serta tingkat produktivitas akan mengalami peningkatan.

Berdasarkan riset lainya yang dilaksanakan Wang et al. (2010) pada karyawan industri di China, ditemukannya hasil bahwasannya keadilan 
organisasional mempunyai hubungan yang signifikan pada komitmen seorang pegawai. Riset yang dilaksanakan oleh Dehkordi et al. (2013) mendapatkan bahwasannya keadilan organisasional memiliki pengaruh positif serta kuat pada komitmen organisasi. Kekurangan keadilan didalam perusahaan akankah membuat komitmen organisasi yang kecil. Riset ini didukung oleh Demirel juga Yucel (2013) bahwasannya keadilan distribusi, keadilan procedural, keadilan interaksional mempunyai korelasi yang positif pada komitmen efektif. Pengelolaan organisasi dapat menggunakan keadilan organisasional sebagai dasar untuk memberikan komitmen organisasional. Penelitian Tafti et al., (2014: 1) serta Thorn (2010:3). Makin tinggi keadilan yang dirasa pegawai dari organisasi, jadi secara langsung akan makin tinggi pula komitmen yang mereka tunjukkan.

$\mathrm{H}_{2}$ : Keadilan organisasional berpengaruh positif dan signifikan terhadap komitmen organisasional

Ibrahim dan Perez (2014) Dalam penelitian yang dilakukan di Arab pada 28 organisasi pelayanan yang berbeda dengan responden sejumlah 174 sampel, menemukan bahwasannya kepuasan kerja memiliki pengaruh positif pada komitmen organisasi pegawai dengan signifikan. Hasil riset dari Tania juga Sutanto (2013) yang memiliki judul Pengaruh Motivasi Kerja dan Kepuasan Kerja Terhadap Komitmen Organisasional Pegawai PT. DAI KNIFE Di Surabaya memberi petunjuk bahwasannya Kepuasan kerja memiliki pengaruh positif serta signifikan pada komitmen organisasional. Hasil riset berikut berasal Karim juga Rehman (2012) memberi petunjuk hubungan yang kuat diantara komitmen organisasi serta kepuasan kerja. Sebagai pegawai yang puas memiliki kecenderungan akan lebih setia pada perusahaannya serta mempertahankan sikap 
Ni Putu Linda Pratiwi dan Made Subudi, Pengaruh Keadilan Organisasional...

positif pada kerjaan mereka. Dikarenakan hal itu, mereka tak bisa untuk merubah kerjaan mereka serta memberi anggapan kerjaan mereka ada yang lebih baik daripada yang lainnya. Supervisor serta manager perusahaan haruslah membuat kepastian bahwasanya pegawai mempunyai tingkatan kepuasan kerja tinggi didalam rangka agar memberi peningkatan tingkat komitmen organisasional pegawai.

Parwita dkk. (2013) memberikan bukti bahwasannya kepuasan kerja memiliki pengaruh positif signifikan pada komitmen organisasional. Dijelaskan bahwasannya di waktu dosen merasa puas dalam kerjaannya, jadi komitmen mereka akanlah makin bagus. Riset berikut dilaksanakan pada Unmas dengan responden sejumlah 110 sampel. Riset yang dilaksanakan Azeem (2010) memberi petunjuk bahwasannya kepuasan kerja bagai memprediksi signifikan dari komitmen organisasional. penelitian terdahulu yang dilakukan Susanj dan Jakopec (2012:2) menyatakan kepuasan kerja mempengaruhi komitmen organisasional secara positif. Hasil penelitian ini juga didukung oleh penelitian Karim (2012:1). Semakin tinggi kepuasan kerja yang dirasakan oleh karyawan, akan semakin tinggi juga komitmen organisasional yang ditunjukkan.

$\mathrm{H}_{3}$ : Kepuasan kerja berpengaruh positif dan signifikan terhadap komitmen organisasional.

Menurut Sutrisna dan Rahyuda (2014) pada penelitian yang dilakukkannya dirumah sakit Tk II Udayana dengan melibatkan 95 paramedis menemukan bahwasannya kepuasan kerja dengan signifikan bisa melakukan mediasi hubungan pengaruh antara keadilan organisasional (distributif, prosedural, dan interaksional) pada komitmen organisasional. Dua elemen penting yang dapat menimbulkan rasa 
komitmen terhadap organisasi yaitu keadilan organisasional dan kepuasan kerja. Bila sebuah instansi bisa memberi rasa adil untuk semua karywannya maka akan timbul rasa kepuasan dari dalam diri karyawan sehingga akan menciptakan suatu komitmen yang kuat terhadap intansi tersebut.

Keadilan organisasional yang dirasakan karyawan akan menciptakan perasaan positif dalam melakukan pekerjaan, yang pada akhirnya hal tersebut membuat karyawan puas akan pekerjaannya. Kepuasan kerja yang dirasakan karyawan akan mampu mendorong karyawan untuk lebih berkomitmen pada organisasinya, karena ketika karyawan merasa lebih dihargai dan diberi kesejahteraan mereka akan lebih nyaman untuk terus bertahan di suatu perusahaan. Hal tersebut menunjukkan bahwa, kepuasan kerja mampu mengarahkan keadilan organisasi menjadi suatu bentuk komitmen organisasional. Sehingga, kepuasan kerja merupakan suatu variabel yang dapat memediasi hubungan keadilan organisasiaonal dan komitmen organisasional. Hal ini didukung oleh Sethi et al. (2013:1), Susanj dan Jakopec (2012:2) yang menemukan bukti bahwasannya kepuasan kerja mampu memediasi pengaruh keadilan organisasionalonal pada komitmen organisasional. Semakin tinggi keadilan organisasional yang dirasakan oleh karyawan, akan meningkatkan kepuasan kerja mereka, yang pada akhirnya kepuasan kerja tersebut mendorong karyawan untuk lebih berkomitmen

Ibrahim dan Perez (2014) juga menemukan bahwa kepuasan berperan dalam keadilan organisasional mempengaruhi komitmen organisasional. Artinya, efek keadilan organisasional diwujudkan melalui kepuasan. Berdasarkan hasil 
penelitian terdahulu tersebut, jadi bisa dilakukan perumusan hipotesis sebagai berikut :

$\mathrm{H}_{4}$ : Keadilan organisasional berpengaruh positif terhadap komitmen organisasional secara tidak langsung melalui kepuasan kerja.

\section{Gambar 1. Kerangka Konseptual}

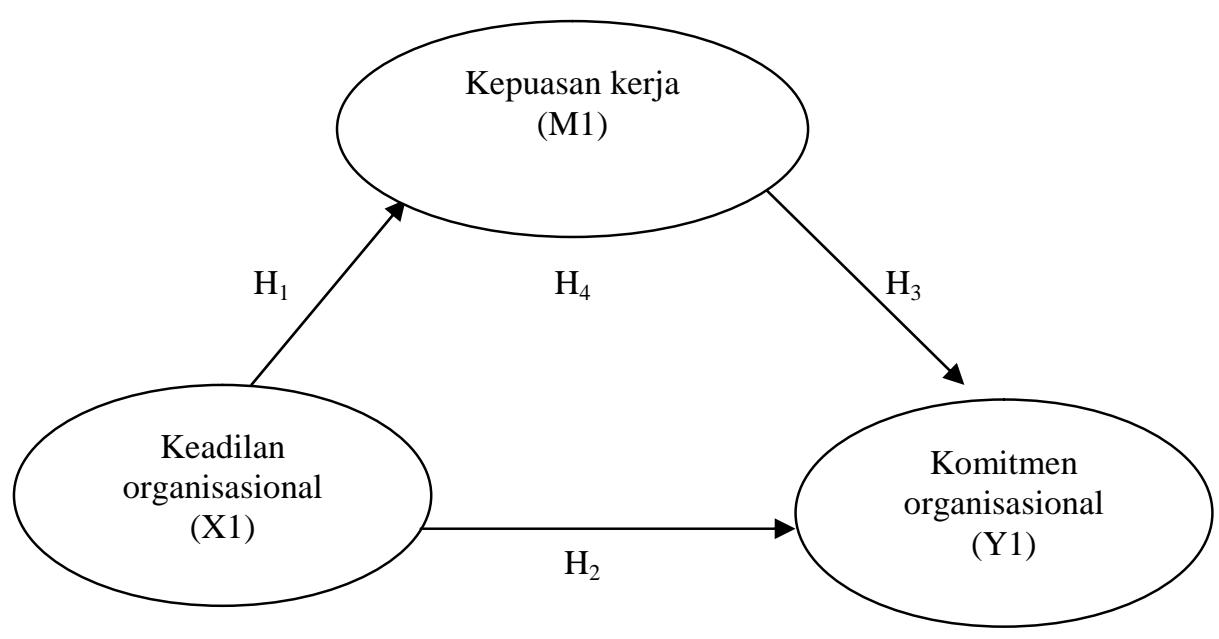

Sumber: Data Diolah, 2018

\section{METODE PENELITIAN}

Pendekatan yang dipakai dalam riset berikut yaitu pendekatan kuantitatif yang memiliki bentuk asosiatif. Rumusan masalah asosiatif yaitu sebuah pendekatan yang memberi petunjuk hubungan diantara dua variable ataupun lebih. Variable didalam penelitian berikut diantaranya keadilan organisasional, kepuasan kerja serta komitmen organsiasional. Lokasi penelitian berikut yaitu pada Dinas Perumahan, Kawasan Permukiman dan Pertanahan Kota Denpasar, yang memiliki lokasi di JL. Mulawarman No.7 Denpasar. Lokasi tersebut terpilih dikarenakan ditemukannya beberapa masalah mengenai keadilan organisasional, kepuasan kerja yang mempengaruhi komitmen organisasional karyawan dan 
belum pernah ada penelitian yang dilakukan di lokasi ini mengenai pengaruh keadilan organisasional terhadap kepuasan kerja dan komitmen organisasional.

Obyek penelitian adalah, keadilan organisasional, kepuasan kerja, dan komitmen organisasional di Disperkim Kota Denpasar. Variabel bebas dalam penelitian ini adalah keadilan organisasional (X1), Variabel mediasi dalam penelitian ini adalah kepuasan kerja (M1), Variabel terikat dalam penelitian ini adalah komitmen organisasional (Y1). Menurut riset AlZu'bi (2010) memberi pernyataan persepsi pegawai memiliki hubungan dengan tiga dimensi daripada keadilan organisasional (X1), meliputi: 1) Keadilan distributif (Distributive Justice) 2) Keadilan Prosedural (Procedural Justice) 3) Keadilan interaksional (Interactional Justice). Adapun indikator kepuasan kerja (M1) menurut Luthans (2006:243), yaitu: 1) Pekerjaan itu sendiri, 2) Gaji, 3) Kesempatan promosi, 4) Pengawas, dan 5) Rekan kerja. Berdasar penjelasan itu bisa dipakai sebagai indikasi didalam menghitung komitmen organisasi yang teradopsi daripada intrumen yang telah berkembang oleh Meyer dan Allen (1991) yaitu: 1) Komitmen afektif (affective commitment) 2) Komitmen berkelanjutan (continuance commitment) 3) Komitmen normatif (normative commitment).

Data kuantitatif dalam penelitian ini adalah jumlah karyawan serta skor jumlah kuesioner yang telah dikalkulasi dengan pembobotan jawaban responden yang terdiri dari data keadilan organisasional, kepuasan kerja, dan komitmen organisasional. Data kualitatif dalam penelitian ini adalah hasil observasi, wawancara dan sejarah Disperkim Kota Denpasar. Sumber primer dalam penelitian ini adalah data yang didapat dari observasi langsung dan kuesioner 
Ni Putu Linda Pratiwi dan Made Subudi, Pengaruh Keadilan Organisasional...

yang disebarkan kepada responden. Data sekunder dalam penelitian ini adalah keberadaan perusahaan, jumlah karyawan dan sejarah perusahaan. Populasi dalam penelitian ini adalah karyawan Disperkim Kota Denpasar yang berjumlah 133 orang. Proporsi pengambilan sampel pada setiap bagian berdasarkan teknik proportionate random sampling karena pengambilan anggota sampel dari populasi dilakukan secara acak tanpa memperhatikan srata yang ada dalam populasi tersebut, berikut rincian jumlah masing-masing sampel di setiap bagian.

Tabel 2. Populasi Dan Sampel Karyawan Dinas Perumahan, Kawasan Permukiman Dan Pertanahan Kota Denpasar

\begin{tabular}{llll}
\hline NO & Jenis Karyawan & Populasi & Sampel \\
\hline 1 & Kasi & 9 & 7 \\
2 & Kasubang & 2 & 2 \\
3 & Kabid & 4 & 3 \\
4 & Pegawai Kontrak & 68 & 50 \\
5 & Staff Pns & 50 & 38 \\
Total & & 133 & 100 \\
\hline Sumber: & Data & &
\end{tabular}

Sumber: Data Diolah, 2018

Pengumpulan data dalam penelitian ini dilakukan digunakan dengan metode sebagai berikut: Observasi, Kuisioner dan Wawancara. Skala yang digunakan dalam metode ini adalah skala Likert. Kemudian indikator tersebut dijadikan sebagai titik tolak untuk menyusun butir-butir pernyataan atau pertanyaan. Skala yang digunakan dalam metode ini adalah skala Likert. Kemudian indikator tersebut dijadikan sebagai titik tolak untuk menyusun butirbutir pernyataan atau pertanyaan. Analisis statistik deskriptif adalah sebuah statistik yang dipakai dalam menganalisis data yang caranya memberikan deskripsi ataupun memberikan gambaran tentang data-data mengenai karakteristik variable penelitian antara lain, mean, standar deviasi, varians, nilai minimum juga 
nilai maksimum (Sugiyono, 2013:207). Analisa statistika deskriptive yang digunakan didalam penelitian berikut yaitu mean, nilai minimum, nilai maksimum.

Teknik analisa data yang dipakai didalam riset berikut adalah teknik analisa jalur (path analysis). Menurut Utama (2011: 156) analisa jalur adalah perluasan daripada analisis linier berganda, untuk menghitung hubungan kausalitas diantara variable yang memiliki jenjang berdasar teori. 1) Membuat diagram jalur dari model penelitian, 2) Membangun persamaan structural. Dilanjutkan dengan uji asumsi klasik. Uji parsial (uji t) disebut juga sebagai uji signifikan individual. Uji ini menunjukan seberapa jauh pengaruh variabel independen secara parsial terhadap variabel dependen (Sugiono, 2012:112). Uji T dilakukan untuk menguji signifikan koefisien korelasi variabel keadilan organisasional (X1) kepuasan kerja (M1) komitmen organisasional (Y1). Koefisien determinasi $\left(\mathrm{R}^{2}\right)$ digunakan mengukur besarnya kontribusi variabel bebas (keadilan organisasi dan kepuasan kerja) terhadap variabel terikat ( komitmen karyawan) secara gabungan dan juga untuk mengetahui ketepatan alat analisis data. Total keragaman data yang dapat dijelaskan oleh model di ukur dengan:

$$
\mathrm{R}_{\mathrm{m}}^{2}=1-\left(\mathrm{e}_{1}\right)^{2}\left(\mathrm{e}_{2}\right)^{2}\left(\mathrm{e}_{3}\right)^{2}
$$

Variabel error (e) merupakan kumpulan variabel bebas lainnya yang tidak dimasukkan dalam sistem penelitian yang dimungkinkan masih mempengaruhi variabel terikat. Pengujian hipotesis mediasi dapat dilakukan dengan Uji Sobel (Sobel Test). Uji Sobel digunakan untuk menguji kekuatan pengaruh tidak 
Ni Putu Linda Pratiwi dan Made Subudi, Pengaruh Keadilan Organisasional...

langsung variabel keadilan organisasional (X1) ke variabel komitmen organisasional (Y1) melalui variabel kepuasan kerja (M1) dinilai dengan membuat perkalian diantara koefisien jalur X1 dengan M1 (a) dengan koefisien jalur M1 terhadap Y1 (b) ataupun ab. Standard error koefisien a dan b ditulis dengan $S_{a}$ serta $S_{b}$ jumlah standard error tak langsung (indirect effect) $S_{a b}$. Pengambilan keputusan didalam proses uji hipotesa pada penelitian berikut yaitu seperti berikut :

Ho : Kepuasan Kerja bukan sebagai variabel pengaruh mediasi pengaruh tidak langsung variabel keadilan organisasional terhadap komitmen organisasional.

$\mathrm{H}_{1}$ : Kepuasan Kerja sebagai variabel mediasi pengaruh tidak langsung variabel keadilan organisasional terhadap komitmen organisasional.

Taraf nyata alpha 0,05 kreteria pengujian yang digunakan adalah sebagai berikut:

$\mathrm{Z}$ hitung $\leq \mathrm{Z}$ tabel, maka $\mathrm{H}_{\mathrm{o}}$ diterima yang berarti $\mathrm{M} 1$ bukan sebagai variabel mediasi.

$\mathrm{Z}$ hitung $>\mathrm{Z}$ tabel, maka $\mathrm{H}_{\mathrm{o}}$ ditolak yang berarti $\mathrm{M} 1$ merupakan variabel mediasi.

Apabila nilai kalkulasi $\mathrm{Z}$ lebih besar dari 1,96 ( dengan tingkat kepercayaan 95 persen), maka variabel mediator dinilai secara signifikan memediasi hubungan antara variabel terikat dan variabel bebas ( preacher dan Hayes, 2004). 


\section{HASIL DAN PEMBAHASAN}

Dari hasil penelitian yang dilakukan pada pegawai di Disperkim Kota Denpasar, maka diketahui karakteristik responden yang meliputi tiga aspek, yaitu tingkat pendidikan, jenis kelamin, serta usia responden. Kuesioner yang disebarkan kepada responden sebanyak 100 kuesioner. Jadi, responden yang digunakan pada karakteristik responden adalah sebanyak 100 orang. Berdasar pada klasifikassi jenis kelamin, hasil riset berikut memberi petunjuk bahwasannya responden terdominasi oleh Laki-laki sejumlah 65 persen, dan Perempuan sejumlah 35 persen.

Mayoritas responden di Disperkim Kota Denpasar berusia 20-30 tahun sebanyak 35 orang dengan persentase 35 persen. Faktor usia dapat menunjang kegiatan organisasi dalam menghasilkan jasa yang berkualitas. Berdasar pada klasifikasi pendidikan terakhir yang terdominasi oleh pegawai yang mempunyai tingkat pendidikan S1 adalah sejumlah 69 persen, lalu diikuti oleh karyawan yang memiliki tingkat pendidikan SMA yaitu sebesar 26 persen, karyawan yang memiliki tingkat pendidikan D3 yaitu sebesar 2 persen, dan yang terakhir karyawan yang emiliki tingkat pendidikan S2 yaitu 3 persen.

Suatu kuesioner biasanya dinyatakan kebenarannya bila pertanyaan kuesioner mengungkapkan data yang diperoleh dari kuesioner itu sendiri. Uji validitas dilakukan dengan cara menghitung korelasi antar skor masing-masing pertanyaan. Jika koefisien korelasi positif dan lebih besar dari 0,3 maka indikator dikatakan valid. Hasil uji validitas memberi petunjuk bahwasannya semua variable mempunyai nilai koefisien korelasi dengan jumlah skor semua item 
Ni Putu Linda Pratiwi dan Made Subudi, Pengaruh Keadilan Organisasional...

pertanyaan lebih tinggi daripada 0,30. Hal tersebut memberi petunjuk bahwasannya tiap butir pertanyaan didalam intrumen riset itu valid. Intrumen dinyatakan valid reliable, apabila intrumen itu mempunyai besaran Cronbach's Alpha lebih daripada 0,60. Hasil daripada uji reliabilitas bisa ditampilkan didalam tabel 3 berikut:

Tabel 3.

Hasil Uji Reliabilitas

\begin{tabular}{clcc}
\hline No. & \multicolumn{1}{c}{ Variabel } & Cronbadh'sAlpha & Keterangan \\
\hline $\mathbf{1}$ & Keadilan Organisasional (X1) & 0,983 & Reliabel \\
$\mathbf{2}$ & Kepuasan Kerja (M1) & 0,964 & Reliabel \\
$\mathbf{3}$ & Komitmen Organisasional (Y1) & 0,941 & Reliabel \\
\hline
\end{tabular}

Sumber: Data Diolah, 2018

Suatu instrumen dinyatakan reliable, apabila instrumen tersebut mempunyai besaran Cronbach's Alpha melebihi daripada 0,60. Hasil uji reliabilitas yang ditampilkan didalam tabel 3 memberi petunjuk bahwasannya tiap variable mempunyai besaran koefisien Cronbach's Alpha melebihi daripada 0,60. Hal itu dapat dikatakan bahwa seluruh variable didalam penelitian berikut reliable.

Nilai rata-rata masing-masing dimensi keadilan organisasional yaitu keadilan distributif 3.75, keadilan prosedural 3.68, keadilan interaksional 3.64 dan nilai rata-rata keadilan organisasional sebesar 3.67 yang mempunyai arti keadilan organisasional yang di terima pegawai termasuk bagus. Nilai rata-rata paling tinggi jawaban responden ditampilkan di pernyataan "Pimpinan memperlakukan saya dengan baik pada saat membuat keputusan pekerjaan". Nilai rata-rata terendah jawaban responden ditunjukkan pada pernyataan " Pimpinan memberikan keadilan untuk keputusan pekerjaan yang dibuat". Variable kepuasan kerja 
mempunyai besaran rata-rata sejumlah 3,87 yang memiliki arti kepuasan kerja yang dirasa pegawai masuk kedalam golongan bagus. Besaran rata-rata paling tinggi jawaban responden ditunjukan di pernyataan "Pekerjaan saya sekarang sesuai dengan keahlian saya" dan "Besarnya gaji yang saya terima sasuai dengan gaji yang saya kerjakan“ dan "Hubungan saya dengan rekan kerja sudah terjalin dengan baik". Nilai rata-rata terendah jawaban responden ditunjukkan pada pernyataan "Pimpinan memperlakukan semua karyawan dengan adil".

Jawaban responden untuk variabel komitmen organisasional mempunyai rata-rata sejumlah 3,68 yang memiliki arti komitmen organisasional pegawai masuk golongan bagus. Nilai rata-rata paling tinggi jawaban responden ditampilkan di pernyataan "Saya sangat senang untuk menghabiskan sisa karir saya di organisasi ini”. Besaran rata-rata paling rendah ditampilkan di pernyataan "Berpindah dari organisasi ke organisasi lain tampak tidak etis untuk saya". Uji normalitas ini bertujuan untuk mengetahui residual dari model regresi yang dibuat berdistribusi normal atau tidak. Pengujian ini dilakukan dengan menggunakan uji Kolmogorov-Smirnov. Data dikatakan berdistribusi normal apabila koefisien Asymp.Sig.(2-tailed) lebih besar dari 0,05.

Tabel 4.

Hasil Uji Normalitas Persamaan Regresi 1

\begin{tabular}{lc}
\hline \multirow{2}{*}{$\mathrm{N}$} & Unstandardized Residual \\
\cline { 2 - 3 } & 100 \\
\hline Kolmogorov-SmirnovZ & 1,209 \\
Asymp.Sig.(2-tailed) & 0,108 \\
\hline Sumber: Data Diolah, 2018 &
\end{tabular}

Berdasarkan Tabel 4 dapat dilihat bahwa nilai Kolmogorov-Smirnov sebesar 1,209. Hasil itu memberikan indikasi bahwasannya model persamaan 
Ni Putu Linda Pratiwi dan Made Subudi, Pengaruh Keadilan Organisasional...

regresi itu beristribusi normal dikarenakan besaran Asymp.Sig.(2-tailed) 0,108 lebih tinggi daripada alpha 0,05 .

Tabel 5.

Hasil Uji Normalitas Persamaan Regresi 2

\begin{tabular}{cc}
\hline $\mathrm{N}$ & \multicolumn{1}{c}{ Unstandardized Residual } \\
\cline { 2 - 2 } & 100 \\
\hline Kolmogorov-Smirnov Z & 1,035 \\
Asymp.Sig.(2-tailed) & 0,234 \\
\hline Sumber: Data Diolah, 2018
\end{tabular}

Berdasar Tabel 5 bisa terlihat bahwasannya nilai Kolmogorov-Smirnov sejumlah 1,034. Hasil itu memberikan indikasi bahwasannya model persamaan regresi itu memiliki distribusi normal dikarenakan besaran Asymp.Sig.(2-tailed) 0,234 lebih tinggi dari alpha 0,05 .

Tabel 6.

Hasil Uji Multikoleniaritas

\begin{tabular}{lcc}
\hline \multicolumn{1}{c}{ Variabel } & Tolerance & VIF \\
\hline Keadilan Organisasional (X) & 0,634 & 1,578 \\
Kepuasan Kerja (Y1) & 0,634 & 1,578 \\
\hline Sumber: Data Diolah, 2018 & &
\end{tabular}

Uji multikolinearitas berikut memiliki tujuan agar melakukan uji di model regresi didapatkan ada atau tidaknya korelasi diantara variable bebas. Model regresi yang tak terdapat multikolinearitas mempunyai besaran tolerance melebihi daripada $10 \%$ ataupun VIF Kurang daripada 10. Tabel 6 menampilkan nilai tolerance juga VIF daripada variable keadilan oganisasional dan kepuasan kerja. Nilai itu menunjukan bahwasannya nilai tolerance bagi tiap variable melebihi besarnya daripada $10 \%$ serta besaran VIF melebihi kecilnya daripada 10 ini memiliki arti model persamaan regresi 2 terbebas daripada multikolinearitas. Besaran sig. daripada variable Keadilan Organisasional sejumlah 0,408 melebihi 
dari 0,05 yang mempunyai arti tidak terdapat pengaruh diantara variable bebas pada absolute residual. Hasil itu menujukkan bahwasannya model yang terbuat tak memiliki kandungan gejala heteroskedastisitas. Nilai sig. daripada variable Keadilan Oganisasional juga Kepuasan Kerja tiap tiap variabel sejumlah 0,331 serta 0,602 . Nilai itu lebih tinggi daripada 0,05 yang memiliki arti tak adanya pengaruh diantara variable bebas pada absolute residual. Hasil itu memberi petunjuk bahwasanya model yang terbuat tak memiliki kandungan gejala heteroskedastisitas.

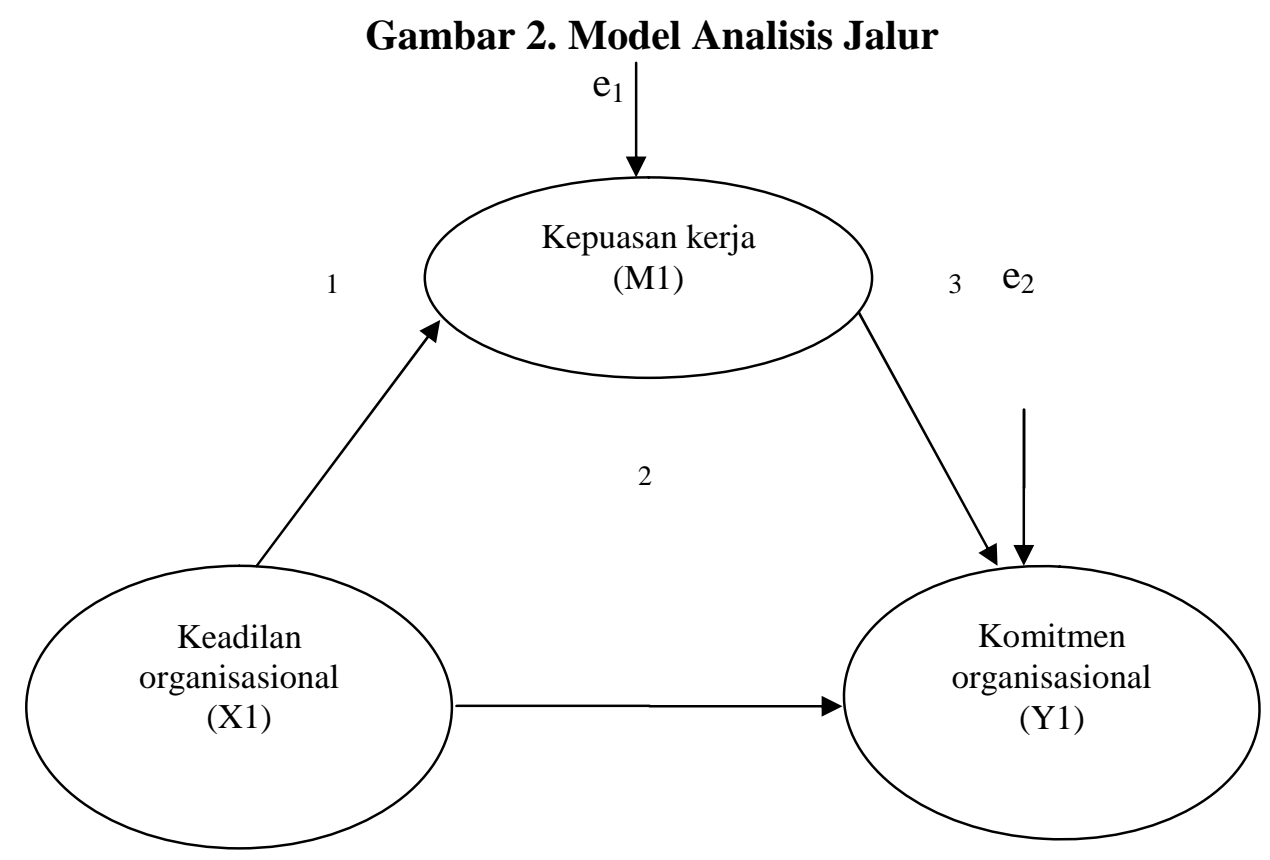

Sumber: Data Diolah, 2018

Analisis jalur merupakan perluasan daripada analisis regresi linear berganda dalam pengujian hubungan kausalitas diantara 2 ataupun lebih variable. Tahaptahap melaksanakan teknik analisis jalur adalah: 1) Merancang model analisis jalur dengan teoritis ditampilkan di Gambar 2. 2) Perhitungan koefisien path, perhitungan koefisien path dilakukan dengan analisis regresi melalui software 
Ni Putu Linda Pratiwi dan Made Subudi, Pengaruh Keadilan Organisasional...

SPSS 17.0 for Windows, diperoleh hasil yang ditunjukkan pada tabel sebagai berikut:

Tabel 7.

Hasil Analisis Jalur Persamaan Regresi 1

\begin{tabular}{lrrr}
\hline Variabel & Standardized Beta & T & Sig. \\
\hline Keadilan Organisasional (X) & $\mathbf{0 , 6 0 5}$ & $\mathbf{7 , 5 2 4}$ & $\mathbf{0}$ \\
R Square & & $\mathbf{0 , 3 6 6}$ \\
F Statistik & $\mathbf{5 6 , 6 1 7}$ \\
Signifikansi & $\mathbf{0}$ \\
\hline Sumber: Data Diolah, 2018 & &
\end{tabular}

Tabel 7 menunjukkan hasil analisis jalur substruktur 1, maka persamaan strukturalnya adalah sebagai berikut:

$$
\begin{aligned}
& \mathrm{Y} 1=\beta_{2} \mathrm{X}+\mathrm{e} 1 \ldots \ldots \\
& \mathrm{Y} 2=0,605 \mathrm{X}+\mathrm{e} 1
\end{aligned}
$$

\section{Tabel 8}

Hasil Analisis Jalur Persamaan Regresi 2

\begin{tabular}{lcrr}
\hline Variabel & Standardized Beta & T & Sig. \\
\hline Keadilan Organisasional (X1) & 0,335 & 5,392 & 0 \\
Kepuasan Kerja (M1) & 0,63 & 10,145 & 0 \\
\hline R $_{\text {Square }}$ Statistik & & $\mathbf{0 , 7 6 3}$ \\
Signifikansi & & $\mathbf{1 5 6 , 3 5 1}$ \\
\hline Sumber: Data Diolah, 2018 & & $\mathbf{0}$ \\
\hline
\end{tabular}

Sumber: Data Diolah, 2018

Tabel 8 memberi petunjuk hasil analisis jalur substruktur 2, jadi persamaan strukturalnya merupakan seperti berikut:

$$
\begin{aligned}
& \mathrm{Y} 2=\beta_{1} \mathrm{X}+\beta_{2} \mathrm{M}+\mathrm{e} 2 \ldots \ldots \ldots \ldots \ldots \ldots \\
& \mathrm{Y} 2=0,335 \mathrm{X}+0,630 \mathrm{M}+\mathrm{e} 2
\end{aligned}
$$

Berdasar pada model substruktur 1 serta substruktur 2, jadi bisa tersusun model diagram jalur akhir. Sebelumnya proses menyusun model diagram jalur akhir, lebih dulu dinilai besaran standar eror seperti berikut : 


$$
\begin{aligned}
& P e_{i}=\sqrt{1-R_{i}^{2}} \\
& \mathrm{Pe}_{1}=\sqrt{1-R_{1}^{2}}=\sqrt{1-0,366}=0,796 \\
& \mathrm{Pe}_{2}=\sqrt{1-R_{2}{ }^{2}}=\sqrt{1-0,763}=0,48
\end{aligned}
$$

Berdasar kepada penghitungan pengaruh error (Pei), didapat hasil pengaruh error $\left(\mathrm{Pe}_{1}\right)$ sejumlah 0,796 serta pengaruh error $\left(\mathrm{Pe}_{2}\right)$ sejumlah 0,487 . Hasil koefisien determinasi total yaitu seperti berikut :

$$
\begin{aligned}
\mathrm{R}^{2} \mathrm{~m} & =1-\left(\mathrm{Pe}_{1}\right)^{2}\left(\mathrm{Pe}_{2}\right)^{2} \ldots \ldots \\
& =1-(0,796)^{2}(0,487)^{2} \\
& =1-(0,634)(0,237) \\
& =1-0,150=0,850
\end{aligned}
$$

Nilai determinasi keseluruhan sejumlah 0,850 berarti bahwasannya variasi komitmen organisasional terpengaruhi oleh variasi keadilan organisasional serta kepuasan kerja, namun sisanya di jelaskan oleh faktor lainnya yang tak masuk kedalam model. Hasil analisis pengaruh keadilan organisasional terhadap komitmen organisasional didapatkan besaran $t_{\text {hitung }}$ sejumlah 5,392 yang lebih besar dari $\mathrm{t}_{\text {tabel }}$ sebesar 1,67 dan nilai koefisien beta 0,335. Nilai $\mathrm{t}_{\text {hitung }} 5,392>1,67$ mengindikasikan bahwa keadilan organisasional berpengaruh positif dan signifikan terhadap komitmen organisasional. Hasil analisis pengaruh keadilan organisasional terhadap kepuasan kerja diperoleh nilai $t_{\text {hitung }} 7,524$ yang lebih besar $t_{\text {tabel }}$ sebesar 1,67 dan nilai koefisien beta 0,605. Nilai $t_{\text {hitung }}$ 7,524>1,67 mengindikasikan bahwasannya keadilan organisasional memiliki pengaruh positif serta signifikan pada kepuasan kerja.

Hasil analisis pengaruh kepuasan kerja pada komitmen organisasional didapatkan besaran $\mathrm{t}_{\text {hitung }} 10,145$ yang lebih besar dari $\mathrm{t}_{\text {tabel }}$ sebesar 1,67 dan nilai koefisien beta 0,630 . Nilai $t_{\text {hitung }} 10,145>1,67$ mengindikasikan bahwa 
Ni Putu Linda Pratiwi dan Made Subudi, Pengaruh Keadilan Organisasional...

kepuasan kerja berpengaruh positif dan signifikan terhadap komitmen organisasional. Hasil koefisien jalur pada hipotesis penelitian dapat digambarkan pada Gambar 3:

\section{Gambar 3. Diagram Jalur Model Penelitian akhir}



Sumber: Data Diolah, 2018

Pengaruh langsung dan tidak langsung serta pengaruh total antar variabel dapat dihitung berdasarkan diagram jalur pada Gambar 3. Uji Sobel dirumuskan dengan persamaan berikut serta bisa dilakukan perhitungan dengan memakai aplikasi Microsoft Excel 2007. Apabila besaran kalkulasi Z lebih tinggi daripada 1,96 (dengan tingkat kepercayaan 95 persen), jadi variable mediasi ternilai dengan signifikan melakukan mediasi hubungan diantara variable terikat serta variable bebas. Perhitungan pengaruh antar variabel dirangkum dalam Tabel 9 sebagai berikut: 


$$
\begin{aligned}
& S_{a b}=\sqrt{\left(0,630^{2}\right) 0,080^{2}+\left(0,605^{2}\right) 0,062^{2}+\left(0,080^{2}\right) 0,062^{2}} \\
& S_{a b}=0,063
\end{aligned}
$$

Tabel 9.

Pengaruh Langsung dan Pengaruh Tidak Langsung serta Pengaruh Total

\begin{tabular}{cccr}
\hline \multirow{2}{*}{$\begin{array}{c}\text { Pengaruh } \\
\text { Variabel }\end{array}$} & $\begin{array}{c}\text { Pengaruh } \\
\text { Langsung }\end{array}$ & $\begin{array}{c}\text { Pengaruh Tidak Langsung Melalui } \\
\text { Kepuasan Kerja (M1) }\end{array}$ & \multirow{2}{*}{$\begin{array}{c}\text { Pengaruh } \\
\text { Total }\end{array}$} \\
\cline { 3 - 3 } & & $\mathbf{( \beta 2} \mathbf{~ \beta 3 )}$ & \\
\hline $\mathrm{X} \rightarrow \mathrm{Y}_{1}$ & 0,420138889 & & 0,420138889 \\
$\mathrm{X} \rightarrow \mathrm{Y}_{2}$ & 0,232638889 & 0,264583333 & 0,497222222 \\
$\mathrm{Y}_{1} \rightarrow \mathrm{Y}_{2}$ & 0,4375 & & 0,4375 \\
\hline \multicolumn{2}{l}{ Sumber: Data Diolah, 2018} &
\end{tabular}

Hasil tabulasi $\mathrm{Z}=6,048>1,96$ dengan tingkat signifikansi $0,000<0,05$ yang memiliki arti kepuasan kerja ternilai dengan signifikansi memlakukan mediasi hubungan diantara keadilan organisasional pada komitmen organisasional. Hasil proses uji hipotesis memberi petunjuk bahwasannya keadilan organisasional memiliki pengaruh positif pada kepuasan kerja. Hasil itu mempunyai arti makin kuatnya keadilan organisasional yang dirasa pegawai jadi kepuasan kerja yang dimiliki oleh karyawan akan semakin meningkat. Hasil pengujian hipotesis memberi petunjuk bahwasannya keadilan organisasional memiliki pengaruh positif pada komitmen organisasional. Hasil itu mempunyai arti makin kuatnya keadilan organisasional yang dirasa oleh pegawai jadi makin kuat pandangan pegawai pada komitmen organisasional. Hasil pengujian hipotesis menunjukkan bahwa kepuasan kerja berpengaruh positif terhadap komitmen organisasional. Hasil tersebut memliki arti makin kuat kepuasan kerja yang dirasakan pegawai jadi dapat meningkatkan pandangan pegawai terhadap 
Ni Putu Linda Pratiwi dan Made Subudi, Pengaruh Keadilan Organisasional...

komitmen organisasional. Hasil pengujian hipotesis menunjukkan bahwa kepuasan kerja dapat melakukan mediasi pengaruh keadilan organisasional pada komitmen organisasional.

\section{SIMPULAN DAN SARAN}

Berdasar kepada hasil pembahasan penelitian yang sudah dilaksanakan, jadi bisa diberi kesimpulan bahwasannya: 1) Keadilan organisasional memiliki pengaruh positif pada kepuasan kerja. Hasil ini memiliki arti bahwasannya makin tingginya tingkat keadilan organisasional yang diterima oleh pegawai jadi semakin tinggi tingkat kepuasan yang dirasakan pegawai. 2) Keadilan organisasional memiliki pengaruh positif pada komitmen organisasional karyawan. Hasil ini memiliki arti bahwasannya makin tingginya keadilan organisasional yang diterima oleh pegawai maka semakin tinggi tingkat komitmen yang dirasakan karyawan kepada organisasi. 3 3) Kepuasan kerja memiliki pengaruh positif terhadap komitmen orgaisasional. Hasil ini berarti bahwa jika kepuasan kerja yang diterima oleh karyawan meningkat maka komitmen organisasional karyawan juga akan meningkat. 4) Kepuasan kerja memediasi pengaruh keadilan organisasional terhadap komitmen organisasional.

Berdasar kepada kesimpulan yang didapatkan jadi saran yang bisa diberikan yaitu seperti berikut: 1) Pimpinan baiknya menjelaskan dengan sangat jelas setiap keputusan pekerjaan yang dibuat. 2) Pimpinan sebaiknya memperlakukan semua karyawan dengan adil. 3) Berpindahnya organisasi ke organisasi lain tampak tak etis bagi karyawan sebaiknya pimpinan tidak selalu memindahkan karyawan ke organisasi lain. 


\section{REFERENSI}

Altahayneh, Ziad Lutfi., Khasawneh, Aman., and Abedalhafiz, Abedalbasit (2014). Relationship between Organizational Justice and Job Satisfaction as Perceived by Jordanian Physical Education Teachers.Asian Social Science, 10 (4), pp. $131-138$.

Al-Zu'bi, Hasan Ali.(2010). A study of relationship between organizational justice and job satisfaction. International Journal of Business and Manajement. Vol.5. No.12. pp. 102-109.

Arabiyat,Bashir,Al Balqaa dan Basma Issa Tlelan Al-Saleem.(2011). The extent of application of the principles of the organizational justice and its relationship to the organizational commitment of the faculty members at the University of Jordan. International Journal of Human Resource Studies. Vol.1. No.2 pp. 52-59.

Astuti Endang Stiti, Kusdi Raharjo and Djahmur Hamid. (2013). The Effect Of Empowerrment Of The Organizational Commitment And The Job Statisfacation Of The Empoyees Of The National Electricity Company (Ltd). Asian Transactions On Basic \& Applied Science,(ATBAS ISSN : 2221-4291) Vol. 03 No. 04.

Azeem, Syed Mohammad. (2010). Job Satisfaction and Organizational Commitment among Employees in the Sultanate of Oman. Department of Management Information Systems. Yanbu University College. Yanbu, Saudi Arabia. Journal of Psychology, 1 (1), pp. 295-299.

Crow, Matthew S. \& Lee,Chang-Bae \& Joo, Jae-Jin. (2012). Organizational justice and organizational commitment among South Korean police officers: An investigation of job satisfaction. Policing: An International Journal of Police Strategies \& Management. 35 (2) pp. $402-423$

Cropanzano, Rusell., Bowen David E., and Gilliand Stephen W. (2007). The Management of Organizationnal Justice. Academi of management percepctives. pp. $34-48$.

Dehkordi, Fariba R., Sardar Mohammadi dan Mozafar Yektayar. (2013). Relationship of organizational justice and organizational commitment of the staff in General Directorate of Youth and Sports in Chahar Mahal Va Bakhtiari Province. European Journal of Experimental Biology. Vol. 3. No. 3. pp. 696-700.

Demirel,Yavus dan Ilhami Yucel.(2013). The effect oforganizational justice on organizational commitment: a study on automotive industry. International Journal of Social Sciences, Vol. 2. 3. pp. 26-37. 
Ni Putu Linda Pratiwi dan Made Subudi, Pengaruh Keadilan Organisasional...

Dessler, Gary. (2010). Manajemen Sumber Daya Manusia. Edisi 10. Jakarta: PT INDEKS

Fatimah, O., Amiraa, A M, and Halim F W. (2011).The Relantionship between Organizational justice, Organizational Citizenship Behavior and Job Satisfaction.Pertanika J. Soc. Sci \& Hum, Vol. 2. No. 9 pp. 115-121

Fatt, Choong Kwai., Khin, Edward W S., and Heng, Tioh N. (2010). The Impact of Organization Justice on Employee's Job Satisfaction : The Malaysian Computer Companies Perspectives. American Journal of Economics and Business Administration. 2(1), pp. 56-63.

Fernandes, Cedwyn.,and Raed Awamleh. (2006). Impact of organisational justice in an expatriate work environment. Journal Management Research News. 29 (11). pp. 701-712.

Handoko, T.Hani. 2008. Manajemen Personalia dan Sumber Daya Manusia, Edisi 2. Yogyakarta : BPFE.

Ibrahim, Mohamed E. Dan Ann O. Perez.(2014). Effects of organizational justice, employee satisfaction, and gender on employees' commitment: evidence from the UAE. International Journal of Business and Management. Vol. 9 No. 2. pp. 45-59.

Jawad, Muhammad., Raja, Sobia., Abraiz, Aneela.,and Tabassum,Tahira M. (2012). Role of Organizational justice in organizational commitment with moderating effect of employee work attitudes. Journal of Business and Management (IOSR-JBM), 5 (4), pp. 39-45.

Karim, Faisal., Rehman, Omar. (2012). Impact of Job Satisfaction, Perceived Organizational Justice and Empoyee Empowerment on Organizational Commitment in Semi-Government Organizations of Pakistan. Journal of Bussines Studies Quarterly, 3 (4),pp. 92-104.

Kartika, Anggi Dyah Ayu, Djamhur Hamid dan Arik Prasetya. (2014). Pengaruh Komitmen organisasional dan disiplin kerja terhadap prestasi kerja karyawan (study pada karyawan tetap PT. Pabrik Gula Toelangan Sidoarjo). Jurnal Administrasi Bisnis. Vol.15.No.2.pp.1-8.

Khan, Muhammad S., Irfanullah Khan, Dr. Ghulam Muhammad Kundi, Dr.Shadiullah Khan, Dr. Allah Nawaz., Farhatullah Khan, dan Naseem Bakht Yar. (2014). The Impact of job satisfacation and organizational commitment on the intention to leave among the academicians. International Journal of Academic Research in Business and Social Sciences. Vol. 4. No.2.pp.114-131. 
Kristanto, Harris. (2015). Keadilan organisasional, komitmen organisasional, dan kineja karyawan. Jurnal Manajemen dan Kewirausahaan. Vol.17. NO. 1. pp. 86-98.

Kusumawati, Yulia dan Made Surya Putra.(2015). Pengaruh keadilan procedural dan keadilan interaksional terhadap perilakuretaliasi karyawan. E-Jurnal Manajemen Universitas Udayana.Vol.4.No.3. pp. 731-749.

Lotfi, Mohammad Hosein dan Mohammad Shirazi Pour. (2013). The relationship between organizational justice and job satisfaction among the employees sciences. Vol.9 No. 3. pp. $2073-2079$.

Luthans, F. (2006). Perilaku Organisasi edisi 10. Yogyakarta: Penerbit Andi Offset.

Luthans, F, (2005). Organizational Behavior, 10th edition. Boston: McGraw-Hill.

Malik, Muhammad Ehsan dan Basharat Naeem. (2011). Impact of perceived organizational justice on organization commitment of faculty: empirical evidence from Pakistan. Interdisciplinary journal of research in business Vol. 1. Iss. 9. pp. 92-98.

Meyer , John P., dan Natalie J. Allen. (1991). A three-component conceptualizational of organizational commitmen. Human Resource Management Review. Vol. 1. No. 1. pp. 61-89.

Naeem,Ayesha T., Freesha dan Zahid Mahmood.(2014). The study of organizational justice,violation of psychological contract and its effect on job satification in paints Indutry of Pakistan. International Journal of Academic Research in Business and Management. Vol.4. No 12.pp.244-251.

Naqvi, S.M.M.R., Maria Ishtiaq, Nousheen Kanwal dan Mohsin Ali. (2013). Impact of Job autonomy on organizational commitment and job satisfaction: the moderating role of organizational culture in fast food sector of Pakistan. International Journal of Business and Management.Vol.8.No.17.pp. 92-102.

Noe, Raymond A., et. Al (2010) Human Resource Management, Gaining Competitive Advantage $3^{\text {rd }}$ Edition. McGraw-Hill.

Oceani, Ni Made Puspita., dan Anak Agung Ayu Srianthi. (2015). Pengaruh Gaya Kepemipinan Tranformasional dan Keadilan Organisasional terhadap Komitmen Organisasional Karyawan Dibagian Housekeeping Pada Hotel Bali Dynasty Resort Kuta. E-Jurnal Management Unud. 4 (10). H. 2921 2927. 
Ogut, E., Mehmet Sahin dan M.Tahir Dermirsel.(2013). The relationship between perceived organizational justice and cyberloafing:evidence from a Public Hospital in Turkey. Mediterranean Journal of social Sciences. Vol. 4. No. 10. pp. 226-223.

Owolabi, Ademola B. (2012). Effect of Organizational Environment on TurnOver Intention of Health Workers in Ekiti State, Nigeria. Departement of psychology University of Ado- Ekiti, Negeria.3, (1),pp. 5-27.

Parwita, Gde Bayu Surya, I Gede Supartha dan Putu Saroyeni. (2013). Penagaruh Kepuasan Kerja Terhadapa Komitmen Organisasional dan Disiplin Kerja. E-Jurnal Ekonomi dan Bisnis Universitas Udayana. Vol. 02 no. 11.

Putra, Wisnu Yogeswara. (2014). Pengaruh Keadilan Organisasional Pada Kepuasan Kerja Dan Turnover Intention Karyawan BPR Di Kabupaten Tabanan. Jurnal Manajemen Udayana, 2 (9), h. 2579-2614.

Putra, A. A. Wisnu Yogeswara dan Made Surya Putra. (2014). Pengaruh keadilan organisasional pada kepuasan kerja dan turnover intention karyawan BPR di Kabupaten Tabanan. E-Jurnal Manjemen Universitas Udayana. Vol. 3. No. 9. pp. 2597-2614.

Puspitawati, Ni Made Dwi dan I Gede Riana.(2014). Pengaruh kepuasan kerja terhadap Komitmen organisasional dan Kualitas layanan. Jurnal Manajemen Strategi Bisnis dan Kewirausahaan. Vol. 3. No. 9. Pp. 25972614.

Rivai, Veinthzal dan Sagala, Ella Januvani.(2011). Manajemen Sumber Daya Manusia untuk perusahaan dari Teori ke Praktik. Edisi Kedua.Jakarta: Raja Grafindo Persada.

Robbins, S.P. dan Judge, T.A. (2007). Organizational Behavior 12th edition. Pearson Prentice-Hall.

Sareshkeh, SK., Ghaziani, F.G., and Tayebi, S.M. (2012). Impact of Organizatioal Justice Perceptions on Job Satisfaction and Organizational Commitment: The Iranian Sport Federations Perspektive. Annals of Biological Research. 3(8), pp. 4229-4238.

Sethi, M dan Hina Iqbal. (2013). "Relationship between Perceived Organizational Justice and the Employees Job Satisfaction". Abasyn Journal of Social Sciences. Vol: 7 Issue: 1.

Suryanatha, A.A. Ngr. Bayu. (2014). Pengaruh Kepemimpinan Tranformasional Dan Komitmen Organisasi Terhadap Kepuasan Kerja Karyawan Dan 
Organisasional Citizenship Behavior (ocb) Pada Baleka Resort Hotel \& Spa Legian. E-Jurnal Manajemen Udayana, 2 (9), $h$ : 2579-2614.

Sugiyono. (2012). Metode Penelitian Bisnis. Bandung: CV. Alfabeta.

Sugiyono. (2014). Metode Penelitian Bisnis. Cetakan ke-18. Bandung: CV. Alfabeta.

Sutrisno, Edy.(2012). Manajemen Sumber Daya Manusia. Jakarta: Kencana Prenada Media Group.

Sutrisna, I Wayan Wira dan Agoes Ganesha Rahyuda. (2014). Pengaruh keadilan distributif, prosedural dan interaksional terhadap kepuasan kerja dan komitmen organisasi pada paramedis di rumah sakit Tk II Udayana Denpasar. E-Jurnal Universitas Udayana. Vol. 3. No. 9. Pp.2489-2509.

Suwardi dan Joko Utomo. (2011). Pengaruh motivasi kerja, kepuasan kerja, dan komitmen organisasional terhadap kinerja pegawai. Analisis Manajemen. Vol. 5. No. 1. Pp. 75-86.

Susanj, Z dan Ana Jakopec, (2012). "Fairness Perceptions and Job Satisfaction as Mediators of the Relationship between Leadership Style and Organizational Commitment". Psychological Topics 21 (2012), 3, 509- 526.

Tania, Anastasia., dan Eddy M. Sutanto. (2013). Pengaruh Motivasi Kerja dan Kepuasan Kerja Terhadap Komitmen Organisasional Karyawan. PT. Dai Knipe Di Surabaya. Jurnal Agora, 1 (3). Pp. 1-9.

Teck-Hong, T., \& Waheed, A. (2011). Herzberg's Motivation- Hygiene Theory and Job Satisfaction in the Malaysian Retail Sector: The Mediating Effect of Love of Money. Asian Academy Of Management Journal, 16 (1).

Thamrin, H M (2012). The influence of Tranformasional Leadership and Organizational Comitment on Job Satisfaction and Employee Perfomance. International Journal of Inovation, Management and Technology, Vol. 3,No.5.

Thorn, D. (2010). "Perceptions of organizational justice, job satisfaction, and organizational commitment in intercollegiate athletics : a study of NCAA men's sport coaches". Electronic Theses and Dissertations. Paper 1440.

Tobing, Diana Sulianti K. L. (2009). Pengaruh komitmen organisasi dan kepuasan kerja terhadap kinerja karyawan PT. Perkebunan Nusantara III di Sumatera Utara. Jurnal Manajemen dan Kewirausahaan. Vol. 11. No. 1. pp. 31-37. 
Ni Putu Linda Pratiwi dan Made Subudi, Pengaruh Keadilan Organisasional...

Utama, Made Suyana. (2011). Aplikasi Analisis Kuantitatif. Edisi Kelima. Diktat Kuliah pada Fakultas Ekonomi Universitas Udayana.

Wang, Xinyan., Liao, Jianqiao., Xia, Degen., and Tao, Chang. (2010). The impact of organizational justice on work performance, mediating effect of organizational commitment and leader-member exchange. International Jornal Of ManPower, 31 (6), pp. 660-677. 